\title{
Breast lesions in women under 25 years: radiologic-pathologic correlation
}

\author{
Abdelhaafez Alawi ${ }^{1}$, Malak Hasan², Mohamed M. Harraz ${ }^{3 *}$ D, Wael Hamza Kamr ${ }^{3}$, Shadiah Alsolami ${ }^{4}$, \\ Hamid Mowalwei ${ }^{5}$, Adulaziz Salem ${ }^{1}$ and Huda Qronfla $^{6}$
}

\begin{abstract}
Background: The majority of breast lesions in women under 25 years are being benign. Imaging is important for diagnosis and selecting patients for further procedures. Although malignancy is rare in this group of patients, suspected lesions must be biopsied. Imaging is very important in the selection of patients for radiological intervention. Understanding of the clinical, pathologic, and imaging features allows the radiologist to guide proper management of these patients. The aim of this study was to determine the frequency of different breast lesions in symptomatic women under 25 years and the value of radiological imaging in the diagnosis.
\end{abstract}

Results: This was a retrospective study; a total number of 250 cases with breast lumps under 25 years of age were registered in the PACKS of our institution in the period from January 01, 2017 to December 31, 2018. Two hundred three cases coped with our inclusion criteria that include available histopathological results either by biopsy or after surgery based on their referring physicians decision. Our exclusion criteria were those cases (47) with definite BIRADS 2 lesions with no available pathology reports. Ultrasonography was done to all patients (203 cases) and MRI was performed to 26 cases. All cases were histologically verified; their findings were reviewed and compared to radiological findings.

A total of 203 symptomatic breast lesions were received at the radiological department in women under 25 years; there were 115 (56.7\%) benign, 85 (41.9\%) cystic, and 3 (1.5\%) malignant lumps. The commonest benign lesion was fibroadenoma (104 cases, 51.2\%) and all the malignant lesions were invasive ductal carcinoma (IDC) (3 cases, 1.47\%). The $p$ value is $>0.05$, so there were no differences between examination using the ultrasonography and the MRI imaging compared to histopathological results.

Conclusions: Most breast lesions in young women are benign. Ultrasonography is an essential first imaging modality in the diagnosis of women under 25 years with breast lesions.

Keywords: Breast lesions, Young female, MRI, US

\section{Background}

The discovery of breast lesions in females under 25 years often causes great worry due to the high incidence of cancer in the adult group. Understanding the effect of the disease on the young female breast allows the radiologist reaching to proper age differential diagnosis. Knowledge of the differential diagnosis of breast lesions in a young female can help to direct appropriate

\footnotetext{
*Correspondence: harrazharraz@live.com

${ }^{3}$ Radiology Department, Mansoura University, Mansoura, Egypt

Full list of author information is available at the end of the article
}

management. The types of breast lesions in young female vary markedly from that for adults, with the former lesions being overwhelmingly benign. After the onset of puberty, most cases of breast masses are benign fibroadenoma. Malignant masses of the breast in young females are rare. Other causes include infection, trauma, and cyst formation. In young females, interventions may give rise to a disfigurement of the breast. Due to this risk and the low incidence of malignancy in this group age, radiological imaging is very important for selecting patients for further procedures. Suspected lesions must be 
a shift to pathological examination [1]. Breast lesions in females younger 25 years are managed differently compared with those older. The first examination done is ultrasonography, whereas mammography for selected cases. Ultrasonography has more accuracy in the diagnosis of dense fibroglandular breasts in young females [2]. Mammography is important in the diagnosis of microcalcifications and suspected masses. MR imaging may be useful for those patients with deeper breast lumps or chest wall lesions [3]. The risk of intervention procedures to the developing breast is much greater than that of the mature breast. So the conservative approach of clinical and ultrasonographic follow-up is more commonly done in young females [4].

\section{Methods}

This was a retrospective study, a total number of 250 cases with breast lumps under 25 years of age were registered in the PACKS of our institution in the period from January 01, 2017 to December 31, 2018. Two hundred three cases coped with our inclusion criteria that include available histopathological results either by biopsy or after surgery based on their referring physicians decision. Our exclusion criteria were those cases (47) with definite BIRADS 2 lesions with no available pathology reports. Ultrasonography was done to all patients (203 cases) and MRI was performed to 26 cases. All cases were histologically verified; their findings were reviewed and compared to radiological findings.

\section{Ultrasound assessment}

The ultrasound examination was performed with the GE Logiq E9 Medical System, using a $7.5 \mathrm{MHz}$ linear array transducer. Real-time gray-scale and doppler images were obtained. The patients were in a supine position and turned slightly to the contralateral side with the ipsilateral upper limb extended cephalad and a pillow placed under the ipsilateral shoulder. The palpable mass was scanned in longitudinal, transverse, and radial planes. The clockface was used to indicate the site of the mass. The masses were evaluated according to their borders, echogenicity, posterior echoes, and depth-width ratio. Each mass was categorized as either benign or malignant. In our study, we classified the breast lesions according to the American College of Radiology (ACR) BIRADS. ACR BI-RADS was to address a lack of standardization and uniformity in practice reporting to improve communication among radiologists, and surgeons (Table 1) [5]. BI-RADS classification for the US is based on an analysis of descriptors from several feature categories (Table 2) [6]. It includes six morphologic features of breast masses: shape, orientation, margin, boundary, internal echo pattern, and posterior acoustic features. The shape is described as oval, round, or
Table 1 BI-RADS US assessment categories

\begin{tabular}{|c|c|}
\hline Assessment & Management \\
\hline $\begin{array}{l}\text { Category 0: incomplete-need } \\
\text { additional imaging evaluation }\end{array}$ & Recall for additional imaging \\
\hline Category 1: negative & Routine screening \\
\hline Category 2: benign & Routine screening \\
\hline Category 3: probably benign & $\begin{array}{l}\text { Short-interval (6 months) follow-up } \\
\text { or continued surveillance }\end{array}$ \\
\hline Category 4: suspicious_biopsy & Tissue diagnosis \\
\hline \multicolumn{2}{|l|}{$\begin{array}{l}\text { Category 4A: low suspicion for } \\
\text { malignancy }\end{array}$} \\
\hline \multicolumn{2}{|l|}{$\begin{array}{l}\text { Category 4B: moderate suspicion } \\
\text { for malignancy }\end{array}$} \\
\hline \multicolumn{2}{|l|}{$\begin{array}{l}\text { Category 4C: high suspicion for } \\
\text { malignancy }\end{array}$} \\
\hline $\begin{array}{l}\text { Category 5: highly suggestive of } \\
\text { malignancy }\end{array}$ & Tissue diagnosis \\
\hline $\begin{array}{l}\text { Category 6: known biopsy-proven } \\
\text { malignancy }\end{array}$ & $\begin{array}{l}\text { Surgical excision when clinically } \\
\text { appropriate }\end{array}$ \\
\hline
\end{tabular}

irregular, and the orientation of a mass can be described as parallel or not parallel (often described as "tallerthan-wide" or "vertical") [7]. When describing mass margins, the most important distinction is between circumscribed and non-circumscribed margins, a feature that distinguishes masses that require a biopsy from masses that can be followed. Circumscribed margins are well defined or sharp. Non-circumscribed margins include micro-lobulated, indistinct, angular, and spiculated. Lesion boundary should be described as an abrupt interface or an echogenic halo which is a suspicious US finding. When defining the internal echo pattern of a lesion, subcutaneous fat within the breast should be used as a reference. Echo pattern descriptors include anechoic, hyperechoic, hypoechoic, isoechoic, and complex. Posterior acoustic features may or may not be seen when imaging breast masses. Posterior acoustic shadowing is a suspicious finding and may be seen in cases of invasive carcinoma, postoperative scar, or macrocalcifications [8]. Although BI-RADS 0 is used frequently at screening mammography, it is less relevant for the US, a modality that commonly completes the diagnostic workup. However, in some instances, additional imaging, such as MR imaging, may be necessary before a final assessment is rendered. BI-RADS 1 (negative) is used if an abnormality is not seen in the US. BI-RADS 2 (benign) is used when the results of the evaluation are negative for malignancy. BI-RADS 3 (probably benign) is a breast mass with circumscribed margins, an oval shape, and parallel orientation that can be classified as category 3 . This mass should have a risk of malignancy of less than $2 \%$. Interval imaging follow-up for lesions categorized as BI-RADS 3 is recommended by Stavros et al. [9]. The BI-RADS 4 is assigned to suspicious lesions for which 
Table 2 BI-RADS US descriptors

\begin{tabular}{llll}
\hline US descriptor & $\begin{array}{l}\text { Features favoring } \\
\text { benign }\end{array}$ & Features favoring malignant & Indeterminate features \\
\hline $\begin{array}{l}\text { Shape of mass } \\
\text { Orientation of mass }\end{array}$ & Oval & Prregular & \\
Margin of mass & Circumscribed & Not parallel to skin & $\begin{array}{l}\text { Micro-lobulated, indistinct, angular, or } \\
\text { spiculated }\end{array}$ \\
Lesion boundary & Abrupt interface & Echogenic halo & \\
Echo pattern & $\begin{array}{l}\text { Anechoic or } \\
\text { hyperechoic }\end{array}$ & Complex & Isoechoic or hypoechoic \\
Posterior acoustic & & Shadowing or combined pattern & Enhancement or no posterior acoustic \\
features & & & features \\
\hline
\end{tabular}

biopsy is recommended. This category is with lesions having a probability of malignancy of approximately 394\%. Therefore, in the ACR BI-RADS atlas, the suggestion now is to subdivide category 4 into three subgroups $(4 \mathrm{~A}, 4 \mathrm{~B}$, and $4 \mathrm{C})$ to better inform the referring clinicians and pathologist of the degree of concern. Category 4A lesions have a low suspicion for malignancy. Category $4 \mathrm{~B}$ is considered to have an intermediate suspicion for malignancy [10]. Category $4 \mathrm{C}$ is used for lesions with moderate suspicion but not classic findings of malignancy. BI-RADS 5 (highly suggestive of malignancy) is reserved for findings that almost represent breast cancer more than 95\%. BI-RADS 6 (known cancer) is for biopsy-proved malignancy [11].

\section{MRI assessment}

MRI Breast was performed using $1.5 \mathrm{~T}$ (Optima GE, USA). The patient was placed prone using a breast coil. The MRI protocol included axial T1, T2, diffusion, STIR, and sagittal STIR sequences contrast was intravenously injected according to the patient's weight using the formula of $0.1 \mathrm{mmol} / \mathrm{kg}$ with a power injector at a rate of 3 $\mathrm{mL}$ per second and flushed with $10 \mathrm{cc}$ of saline and dynamic T1-weighted fat-saturated sequences obtained in pre-contrast and post-contrast $(60,120,180,240,300$, and $360 \mathrm{~s}$ after contrast administration) phases for bilateral breasts. Post-processing allows the generation of the maximum intensity projection (MIP), digital subtraction sequences, and the kinetic curves. Scanning slice thickness should be $3 \mathrm{~mm}$ or less and resolution should be 1 $\mathrm{mm}$ or less in order to minimize volume averaging. MRI offers the advantage of 3D imaging, which is better at detecting smaller lesions than 2D imaging because 2D imaging produces gaps between slices in which a small lesion may be missed. To optimize the contrast between a tumor and surrounding breast parenchyma, the technique must be excellent. Fat suppression is important in contrast-enhanced imaging of the breast because lesion identification in breast MRI relies upon the subtraction of pre- and post-contrast images. In pre-contrast T1 images, the bright, fatty signal from the breast can lead to mis- or overdiagnosis. By canceling out the fat signal within the breast and then using subtraction images, the ability to identify enhancing lesions becomes more accurate. The axial T2 images are reviewed, as these are fluid sensitive and are excellent for finding cysts, fluid, and inflammation. The $\mathrm{T} 2$ images also provide the best evaluation of breast anatomy and skin. The T1 images are also excellent for evaluating intraductal blood and lymph node.

In our study, we classify the breast masses by MRI according to American College of Radiology (ACR) BIRADS lexicon (Table 3). All final impressions should be complete with each lesion fully categorized [12]. It includes describing the mass; shape: lobulated, round, or oval; margin: circumscribed, not circumscribed, irregular, or spiculated; and the internal enhancement characteristics homogeneous, heterogeneous, or rim enhancement. The non-mass enhancement (NME), distribution: focal, linear, segmental, regional, multiple regions, or diffuse; internal enhancement patterns: homogeneous,

Table 3 BI-RADS MRI assessment categories and management

\begin{tabular}{|c|c|}
\hline Assessment & Management \\
\hline $\begin{array}{l}\text { Category 0: incomplete-need } \\
\text { additional imaging evaluation }\end{array}$ & $\begin{array}{l}\text { Recommend additional imaging: } \\
\text { mammogram or targeted US }\end{array}$ \\
\hline Category 1: negative & $\begin{array}{l}\text { Routine breast MRI screening if } \\
\text { cumulative lifetime risk } \geq 20 \%\end{array}$ \\
\hline Category 2: benign & $\begin{array}{l}\text { Routine breast MRI screening if } \\
\text { cumulative lifetime risk } \geq 20 \%\end{array}$ \\
\hline Category 3: probably benign & $\begin{array}{l}\text { Short-interval ( } 6 \text { months) follow-up } \\
\text { If the finding is visible on e.g., US, the } \\
\text { most widely available method should } \\
\text { be used for follow-up (should be ap- } \\
\text { plied only to lesions not fitting cat- } \\
\text { egories II and IV, probably benign } \\
\text { findings in high-risk screening should } \\
\text { rather be biopsied than followed up) }\end{array}$ \\
\hline Category 4: suspicious & Tissue diagnosis \\
\hline $\begin{array}{l}\text { Category 5: highly suggestive of } \\
\text { malignancy }\end{array}$ & Tissue diagnosis \\
\hline $\begin{array}{l}\text { Category 6: known biopsy- } \\
\text { proven malignancy }\end{array}$ & $\begin{array}{l}\text { Surgical excision when clinically } \\
\text { appropriate }\end{array}$ \\
\hline
\end{tabular}


Table 4 Types, frequency, and percentage of the breast lesion in the examined young female

\begin{tabular}{llll}
\hline Breast lesions classification & & Frequency & Percentage \\
\hline Cystic lesions & Fibrocystic change & 54 & $26.6 \%$ \\
& Abscess and mastitis & 19 & $9.35 \%$ \\
& Mammary duct ectasia & 5 & $2.46 \%$ \\
& Galactoceles & 3 & $1.47 \%$ \\
& Hematomas & 2 & $0.98 \%$ \\
Total cystic lesion & & 85 & $41.9 \%$ \\
Benign masses & Fibroadenoma & 104 & $51.2 \%$ \\
& Intraductal papilloma & 4 & $1.97 \%$ \\
& Intramammary lymph node & 4 & $1.97 \%$ \\
Total benign masses & Lactating adenoma & 2 & $0.98 \%$ \\
Malignant masses & Adenomyoepithelioma & 1 & $0.49 \%$ \\
Total malignant masses & Fibroadenomatoid hyperplasia & 2 & $0.98 \%$ \\
\hline
\end{tabular}

heterogeneous, clumped, or clustered ring. Associated features are as follows: nipple retraction, nipple invasion, skin retraction, skin thickening, skin invasion, axillary adenopathy, pectoralis muscle invasion, and chest wall invasion. The kinetic curve is as follows: type I (progressive enhancement pattern usually considered benign), type II (plateau pattern, considered concerning for malignancy), and type III (washout pattern, considered strongly suggestive of malignancy). Category 0 is as follows: incomplete-use this for a finding that needs additional imaging evaluation. This may be used for a technically unsatisfactory scan or when more information is needed to interpret the scan. Category 1 is as follows: negative, this is a normal examination. No abnormal enhancement was found. Category 2 includes the following: benign-like category such as intra-mammary lymph node, enhancing and nonenhancing fibroadenomas, cysts, old non-enhancing scars or recent scars, postoperative collections, fat-containing lesions (such as oil cysts, lipomas, galactoceles, and hamartomas). Category 3 is a follows: probably benign, a finding assessed using this category should have $a \leq 2 \%$ likelihood of malignancy, but greater than the essentially $0 \%$ likelihood of malignancy of a characteristically benign finding. A probably benign finding is not expected to

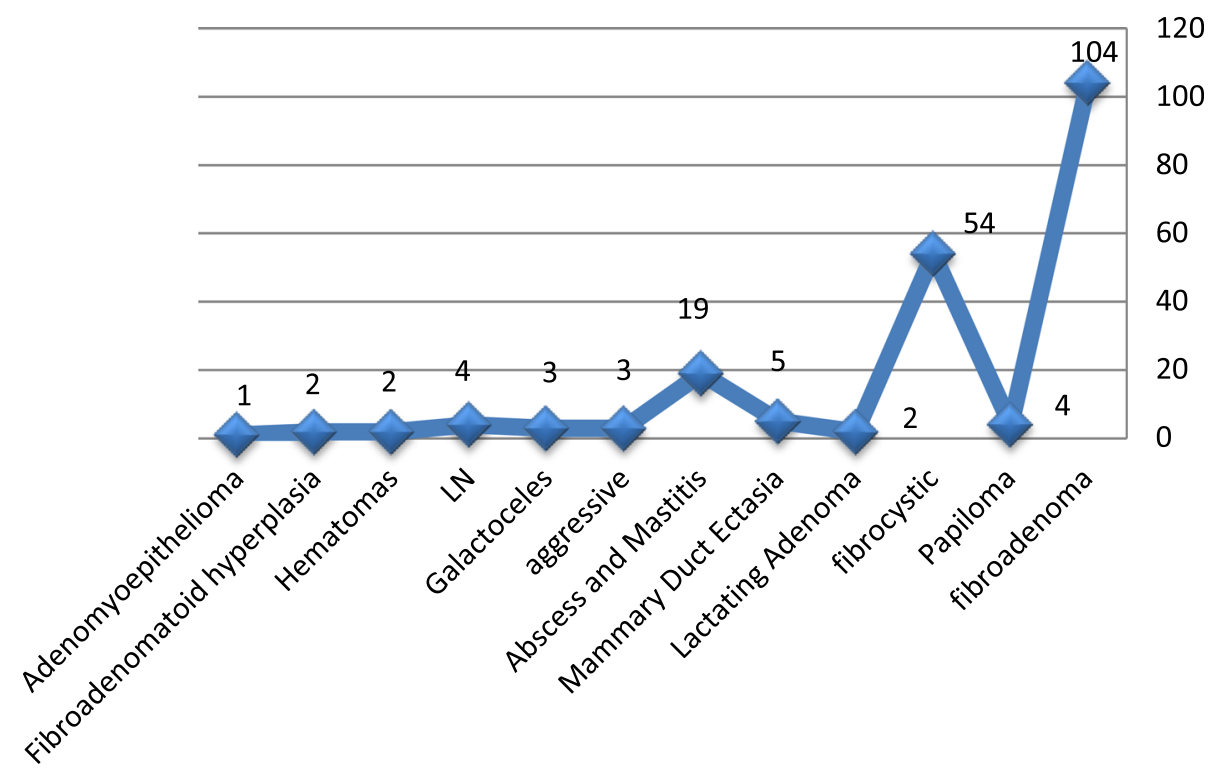

Fig. 1 Frequency of the breast lesion in the examined young female 


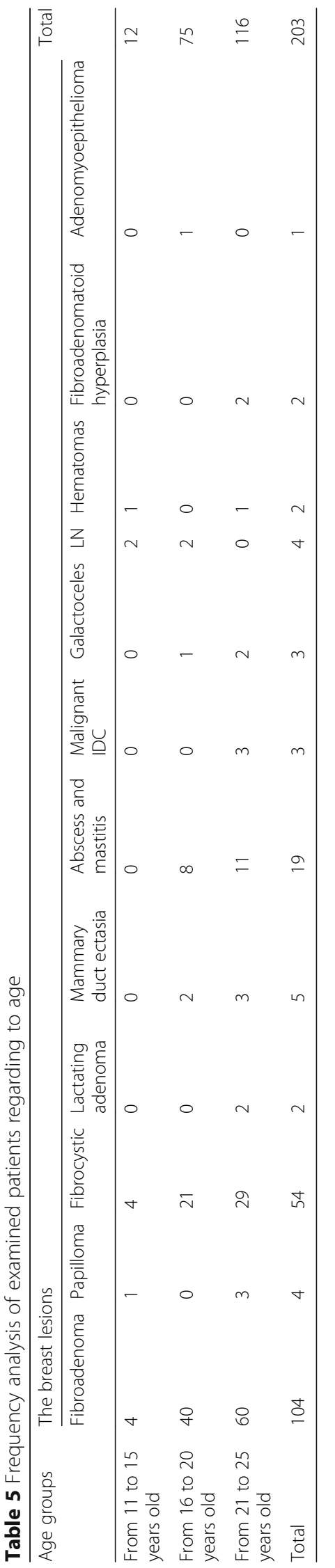




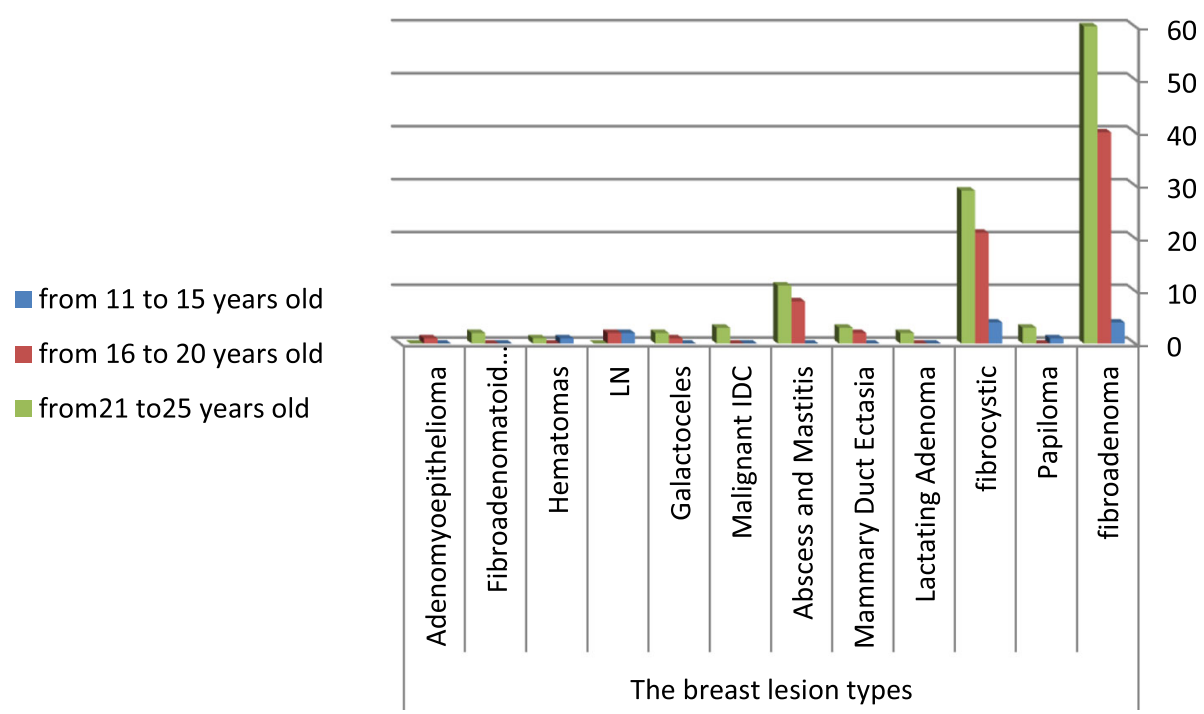

Fig. 2 Breast lesion in the examined young female according to age group

change over the suggested period of imaging. Category 4, suspicious of this category is reserved for findings that do not have the classic appearance of malignancy but are sufficiently suspicious to justify a recommendation for biopsy. For a category 3 assessment is a $2 \%$ likelihood of malignancy and for a category 5 assessment is $95 \%$, so category 4 assessments cover the wide range of likelihood of malignancy in between. In breast MRI, assessment category 4 is not currently divided into subcategories $4 \mathrm{~A}, 4 \mathrm{~B}$, and $4 \mathrm{C}$. Category 4 is used for the majority of findings prompting breast intervention, which can be performed by percutaneous biopsy, by US or stereotactic guidance, or by MRI guidance for lesions not visible at either US or mammography. Category 5 is highly suggestive of

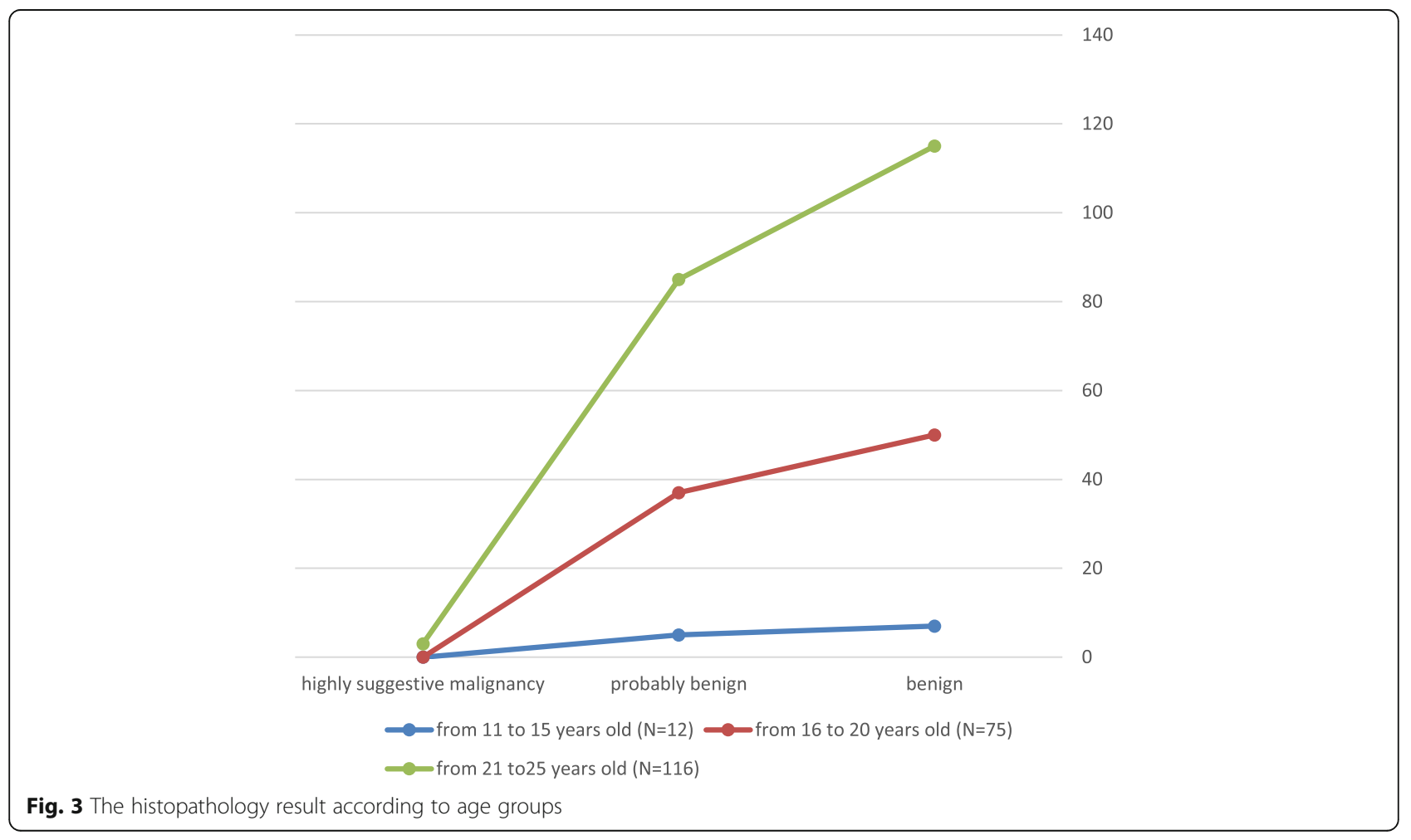


Table 6 Frequency analysis of examined patients regarding to age, BIRADS classification, and pathological results

\begin{tabular}{|c|c|c|c|c|c|c|c|c|c|}
\hline \multirow[t]{4}{*}{ Age group } & \multirow{4}{*}{$\begin{array}{l}\text { No. of } \\
\text { exam. Pat. }\end{array}$} & \multicolumn{8}{|c|}{ Type of examination } \\
\hline & & \multicolumn{3}{|c|}{ The ultrasonographic BI-RADS } & \multicolumn{3}{|c|}{ The MRI BI-RADS } & \multicolumn{2}{|c|}{ Histopathology result (benign vs malignant) } \\
\hline & & \multicolumn{3}{|l|}{203} & \multicolumn{3}{|l|}{26 of 203} & \multicolumn{2}{|l|}{203} \\
\hline & & BIRADS 2 & BIRADS3 & BI-RADS 5 & BIRADS2 & BIRADS3 & BIRADS 5 & Benign & Malignant \\
\hline \multicolumn{2}{|c|}{ From 11 to 15 years old } & 11 & 1 & 0 & 0 & 1 & 0 & 12 & 0 \\
\hline \multicolumn{2}{|c|}{ From 16 to 20 years old } & 72 & 3 & 0 & 0 & 8 & 0 & 75 & 0 \\
\hline \multicolumn{2}{|c|}{ From 21 to 25 years old } & 103 & 10 & 3 & 0 & 14 & 3 & 113 & 3 \\
\hline \multicolumn{2}{|l|}{ Total } & 186 & 14 & 3 & 0 & 23 & 3 & 200 & 3 \\
\hline \multicolumn{2}{|c|}{ Total percent } & $92 \%$ & $6.7 \%$ & $1.5 \%$ & $0 \%$ & $88 \%$ & $12 \%$ & $98.5 \%$ & $1.5 \%$ \\
\hline
\end{tabular}

malignancy; these assessments carry a very high probability ( $\geq 95 \%)$ of malignancy. Category 6 is known biopsyproven malignancy [13].

\section{Result}

A total of 203 of symptomatic breast lesions were examined at the radiology department from January 1, 2017 to December 31, 2018 in women under 25 years. The cases were stratified by age into those $10-15$ years, 12 cases (5.9\%); between 16 and 20 years, 75 cases (36.9\%); and those between 21 and 25 years, 116 cases (58.4\%). The lesions were primarily class into cystic, benign, and malignant lesions. There were 115 cases $(56.7 \%)$ benign, 85 cases $(41.9 \%)$ cystic, and 3 cases $(1.47 \%)$ malignant lumps (Table 4). The largest group comprised fibroadenoma representing 104 cases (51.2\%) followed by fibrocystic change representing 54 cases (26.6\%), abscess 19 cases
(9.35\%), mammary duct ectasia 5 cases $(2.46 \%)$, intraductal papilloma 4 cases (1.97\%), intramammary lymph node 4 case $(1.97 \%)$, galactocele 3 cases $(1.47 \%)$, hematomas 2 cases $(0.98 \%)$, fibroadenomatoid hyperplasia 2 cases $(0.98 \%)$, lactating adenoma 2 cases $(0.98 \%)$, and adenomyoepithelioma 1 case $(0.49 \%)$; however, the malignant group represents 3 cases (1.47\%) and were intraductal carcinoma (Fig. 1). According to age group (Table 5) (Figs. 2 and 3), women from 11 to 15 years were 12 cases including fibroadenoma 4 cases, fibrocystic disease 4 cases, intramammary lymph nodes 2 cases, papilloma 1 case, hematoma 1 case. From 16 to 20 years was 75 cases including fibroadenoma 40 cases, fibrocystic disease 21 cases, abscess 8 cases, mammary duct ectasia 2 cases, intramammary lymph nodes 2 cases, galactocele 1 case, adenomyoepithelioma 1 case. From 21 to 25 years was 116 cases including fibro adenoma 60 cases, fibrocystic disease 29 cases, abscess 11 cases, papilloma 3 cases, mammary

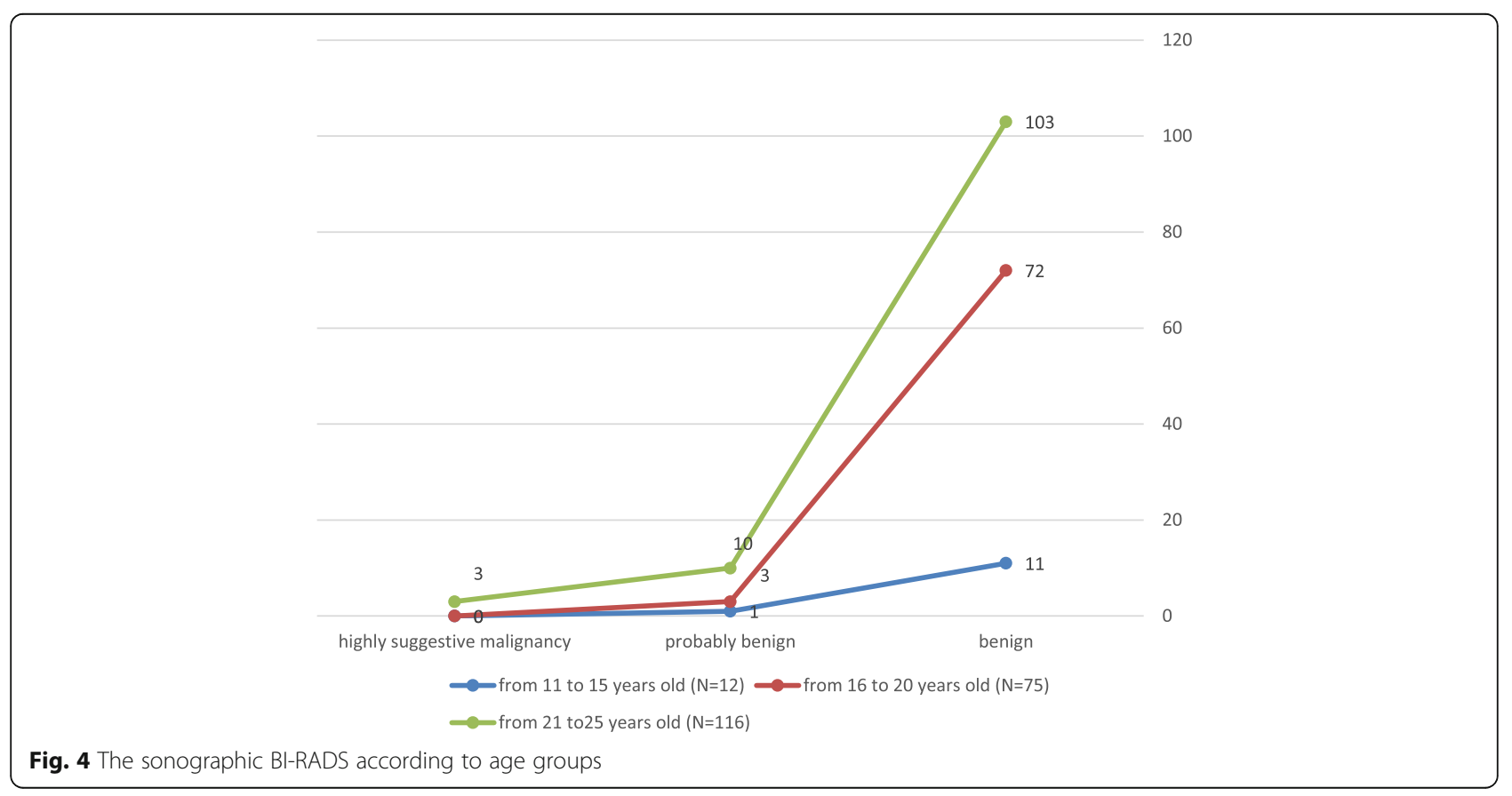


duct ectasia 3 cases, intraductal carcinoma 3 cases, lactating adenoma 2 cases, galactocele 2 cases, fibroadenomatoid hyperplasia 2 cases, and hematoma 1 case. Seventeen patients of 203 who classified by the US as 14 cases BIRADS 3 (with a strong family history of cancer breast) and 3 cases BI-RADS 5 were proceeding directly to MRI; the same category in MRI and their pathology results were also the same 14 cases were benign and the 3 cases were intraductal carcinoma. One hundred eighty-six patients of 203 continued the 3-6 month-interval follow-up, 9 patients of 186 (were US BI-RADS category 2) showed an increase in size and changes of US features and need MRI; their category in MRI was changed to BI-RADS category 3 (strong family history of cancer breast) and their pathology results were benign (Table 6) (Figs. 4 and 5), for all radiological findings compared with pathological results.

\section{Discussion}

Breast masses that occur in the young females are of a benign nature with extremely rare exceptions. The young female generally does not consider themselves to be at risk for breast cancer. However, breast cancer can occur at any age and women of every age should be aware of risk factors and breast self-examination techniques. The incidence of breast cancer increases with age, doubling about every 10 years until menopause. Diagnosis of breast cancer in young females is more difficult because of their denser breast tissue [14]. We have found in our study that pathologic types of breast disease in women under 25 years are broad and this agrees with Leong et al. [15]. In our study, we found that a large number of patients complain of breast lump are between 21 and 25 years 116 cases (58.4\%), followed by $16-20$ years 75 cases (36.9\%), then $10-15$ years 12 cases (5.9\%). Similar results were reported by Olu-Eddo and Ugiagbe [16]. According to Ellen et al. [1], classification, in our study divided the lesions into cystic, benign, and malignant lesions. One hundred fifteen (49.2\%) lesions were benign cases, 3 (1.4\%) were malignant lumps, and 85 cases were cystic. In our study, the majority of breast masses in women under 25 years are benign including tumors and inflammatory conditions representing approximately $89.2 \%$ and $9.36 \%$ respectively. This observation is compatible with an Indian study conducted by Malik and Bharadwaj [14]. In the current study, fibroadenomas are found in 104 cases $(51.2 \%)$ constituted the largest group of benign lumps, followed by 54 (26.6\%) cases of fibrocystic disease, then inflammatory lesions 19 cases (9.36\%). Malignant lumps constituted 3 cases (1.4\%) and all were infiltrating duct cell carcinoma and this cope with finding reported by Egwuonwu et al. [17]. Regarding benign masses, fibroadenomas are found in in 104 cases $(51.2 \%)$ constituted the largest group of benign lumps and more common between 21 and 25 years $(60$ cases) and this agrees with Valeur et al. [18] that revealed fibroadenomas are the most common benign

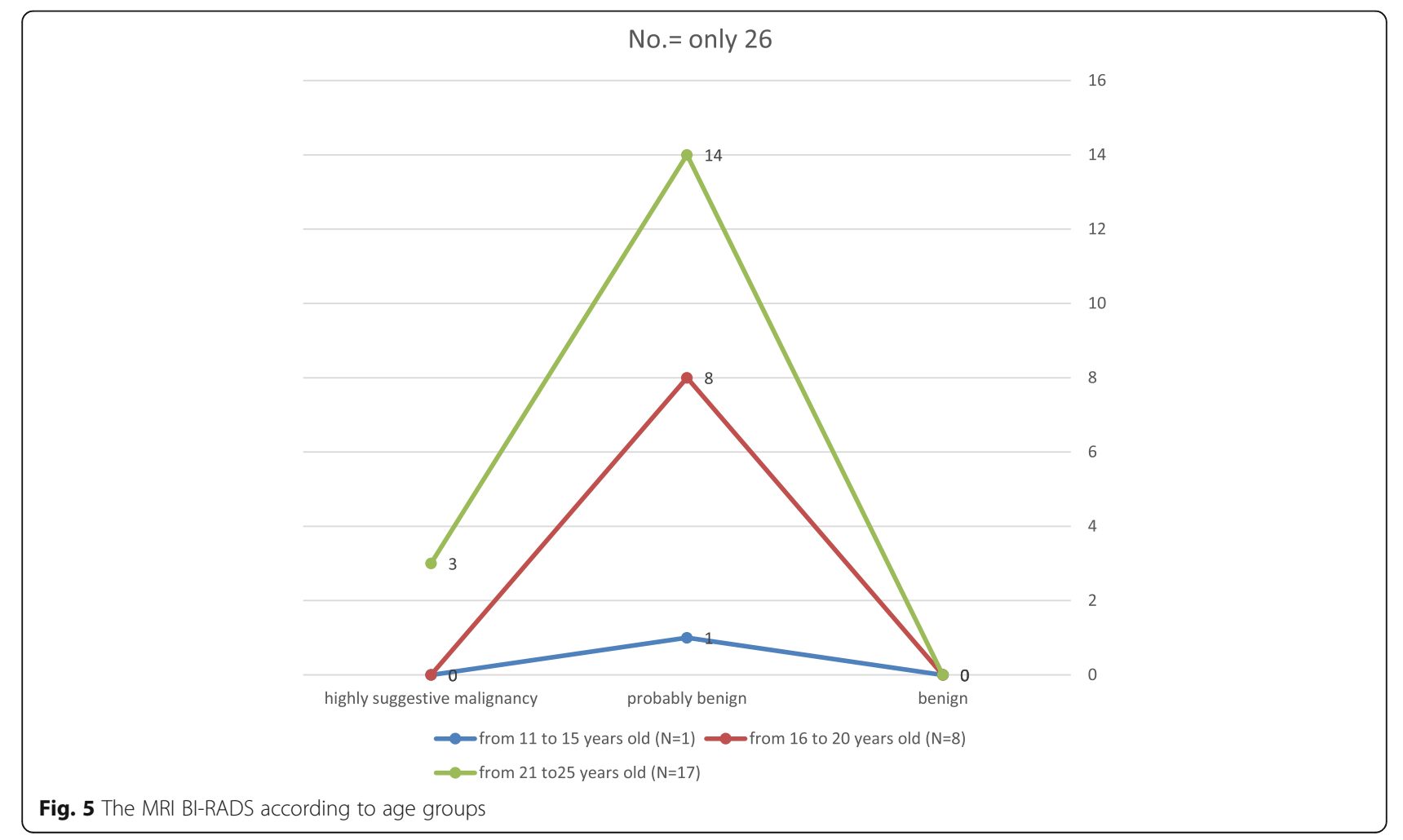



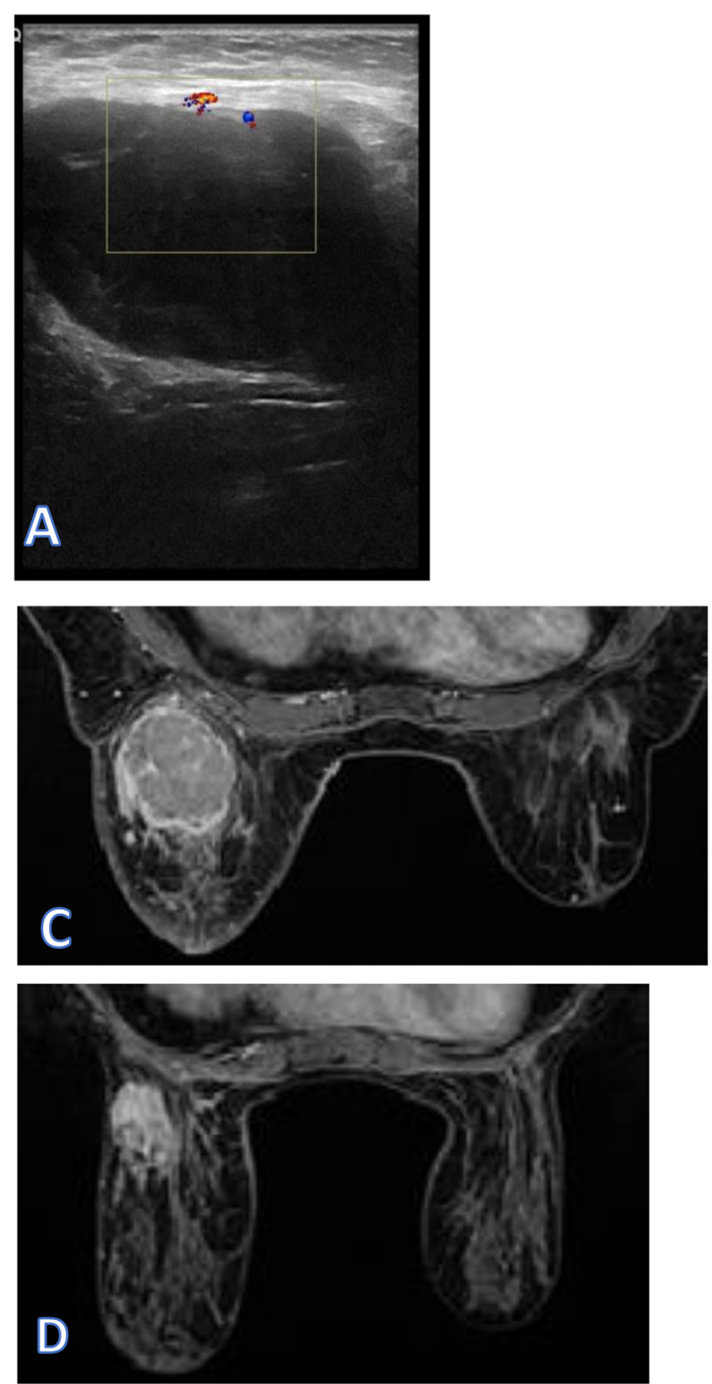
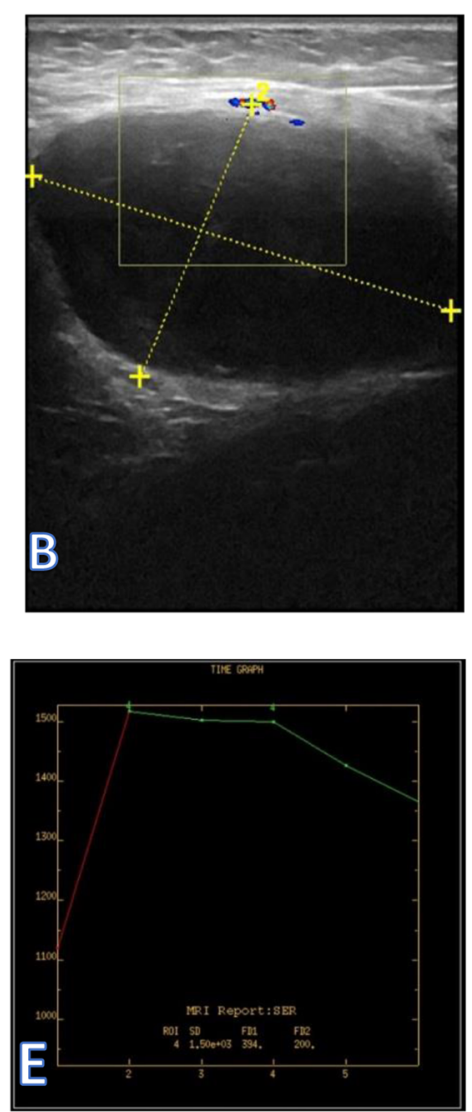

Fig. 6 A 24-year-old patient complains of right breast lump. a and $\mathbf{b}$ US revealed right axillary tail large complex hypo echoic lesion with area of breakdown, slightly micro-lobulated margin, and mild echogenic halo boundary is noted (BIRADS V classification). c-e MRI revealed that the mass shows rim enhancement with rapid washout (type III enhancement pattern in kinetic time intensity curve) (category $V$ according to MRI LEXICON classifications). Biopsy revealed intraductal carcinoma

tumors in young female patients, accounting for 54-94\% of cases. In our study, intraductal papilloma 4 cases (1.97\%) and this agree with Greydanus et al. [19] that revealed it is an uncommon benign disease that occurs in young females. In our study, the intramammary lymph nodes were 4 case $(1.97 \%)$. Intramammary lymph nodes are present in up to $47 \%$ of breasts. Although they are usually located in the upper outer quadrant, they may appear anywhere in the breast [20]. In our 2 cases of lactating adenoma, patients were lactating in the age group 21-25 years and this agrees with Coffin [21] that revealed lactating adenomas predominantly consist of lobules with lactational changes that develop in late pregnancy. Fibroadenomatoid hyperplasia and adenomyoepithelioma are rare benign breast lesions [22, 23]; in our study, they were 2 cases and one case respectively. Regarding cystic lesions in our study, fibrocystic disease is the most common pathology and after fibroadenoma in general benign lesions, it was 54 cases (26.6\%), the majority at 21-25 years about 29 cases and this agrees with Guray and Sahin [24] that revealed fibrocystic change is most often diagnosed between the ages of 20 and 40. Inflammatory changes and abscess 19 cases (9.35\%) between age group 16 and 25 years, 12 cases were lactating and this agrees with Chung et al. [25] that revealed mastitis and abscess are common in lactating women. In our study, we found 5 cases duct ectasia, 3 cases galactocele, all are lactating in the age group 1625 years, and 2 cases hematoma with past history of trauma; duct ectasia is a rare entity that occurs in young 
patients, clinically, patients with duct ectasia present with bloody discharge from the nipple or a palpable mass in the breast [26]. Galactocele is a retention cyst filled with milk caused by obstruction of a lactiferous duct. It is commonly seen in pregnant or lactating women [25]. Hematoma may be associated with a history of breast trauma or surgery. A recent history of trauma or surgery is essential for the diagnosis [26]. Malignancy of breasts is very rare in this age group (Ashikori et al. [27]). Malignant neoplasm in our study represents $1.44 \%$ of lumps. Although this accounts for the smallest group in the study, however still this frequency in young women under 25 years is high and this agrees with Leong et al. [15]. The malignant lesions are present between 21 and 25 years in agreement with Ambreen et al. [28]. The breast cancers in our study appeared more frequently as mass-type lesions and this agrees with Bullier et al. [29] that reveal most of the breast cancers in women younger than 25 years of age were palpable, and palpability was associated with advanced stage and more aggressive features. This suggests that women under 25 years with palpable lumps should be evaluated adequately to avoid delays in the diagnosis of palpable breast cancer, regardless of the very low incidence of breast cancer before 25 years of age. In our study, the 3 malignant breast cases had a positive family history and this agrees with Gordon et al. [30] that reveal family history is a very important risk factor that should be considered with breast cancer, for women with a family history of breast cancer in both a mother and a sister. In our study, the US could detect all the lesions. Because the majority of patients had palpable lumps, targeted US examinations could also improve cancer detection and this agrees with Y.Y. An et al. [31]. In our study, among 26 cases shifting to MRI examination, 3 cases were assigned to US BI-RADS category 5 and the same category in MRI which proved to be malignant by pathological results (Fig. 6). Fourteen cases were assigned to US BI-RADS category 3, the same category in MRI and their pathology results were benign
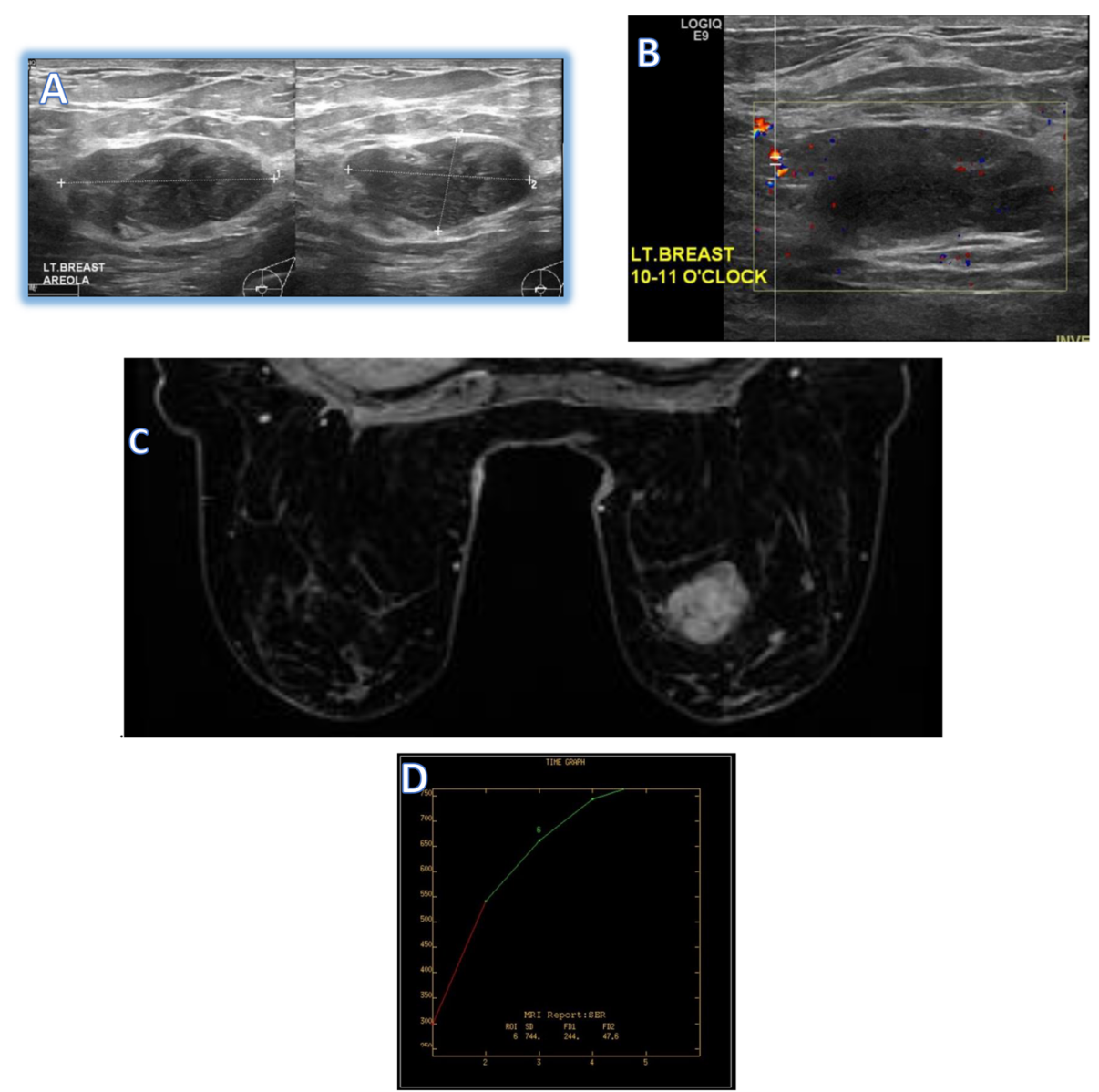

Fig. 7 A 22-year-old patient with history of left breast lump and strong family history of cancer breast. a and $\mathbf{b}$ US shows lobulated hypoechoic mass with vascularity inside (BIRADS III). $\mathbf{c}$ and $\mathbf{d}$ MRI revealed that mass appeared lobulated showed homogenous enhancement (type I kinetic time intensity curve) (category III MRI lexicon classifications) and biopsy confirmed fibro adenoma 

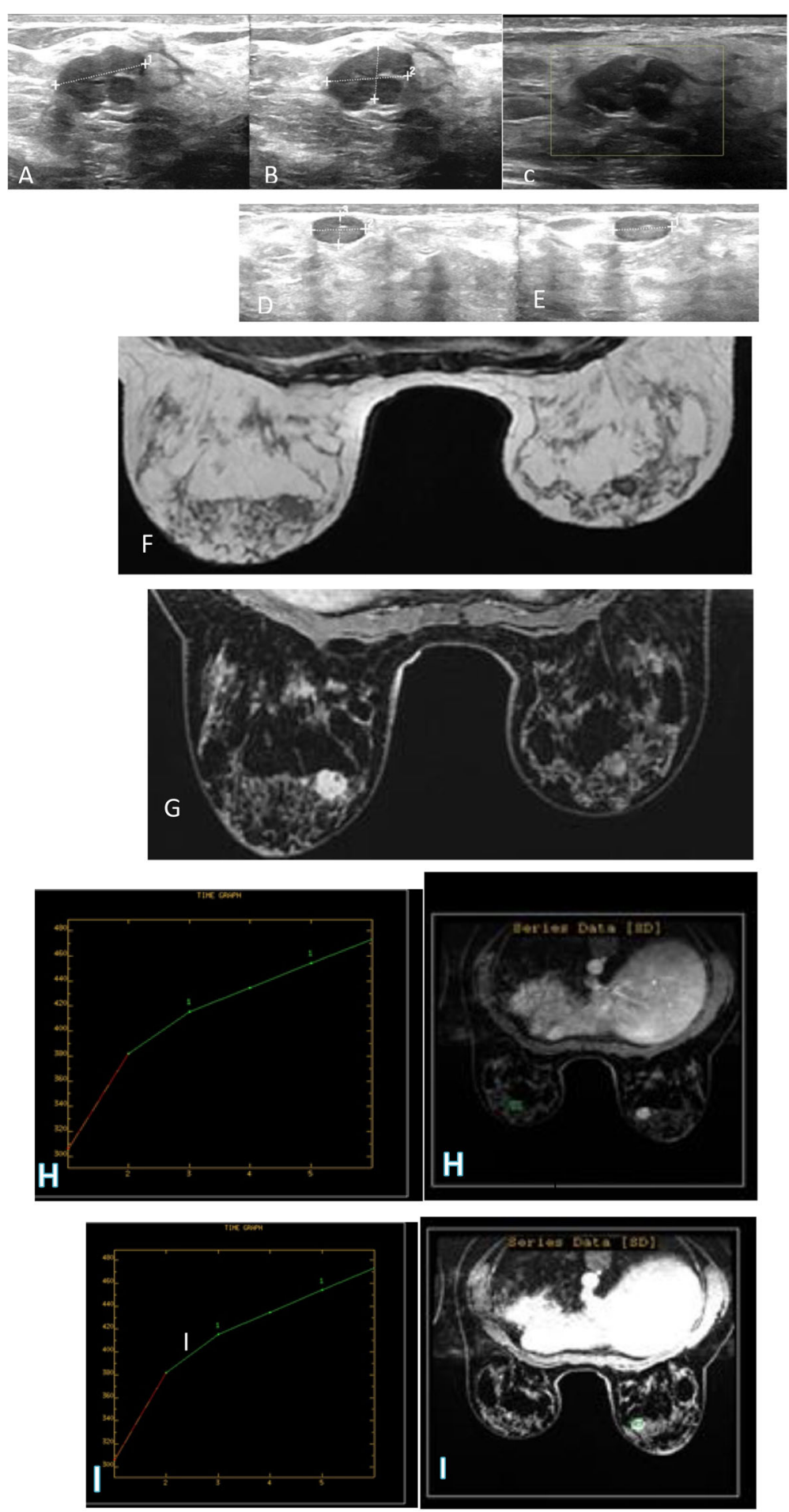

Fig. 8 A 25-year-old patient with history of bilateral breast lumps and strong family history of CA breast. Right breast mass (a and b) US shows hypoechoic mass (BIRAD II), c 3-month follow-up shows increasing in size and more lobulation (change to BIRADS III). The left breast mass (d) US shows smooth outline hypoechoic mass (BIRAD II, e 3-month follow-up shows no significant changes (BIRAD II). f and $\mathbf{g}$ MRI, T1, and postcontrast study detected the masses in both sides, the right one is lobulated and the left one is smooth margin, $\mathbf{h}$ and $\mathbf{i}$ ) images revealed that the right mass shows type I enhancement pattern in kinetic time intensity curve (BIRAD III) and the left mass shows type I enhancement pattern in kinetic time intensity curve (BIRADS II). Biopsy confirmed fibro adenoma on both sides 
(Fig. 7), the remaining 9 cases were assigned to US BIRADS category 2 but shift to MRI examination due to increasing size, changes in its shape in the US follow-up 3-6 month, and due to their strong family history of breast cancer; their category in MRI was changed to BIRADS category 3 and their pathology results were benign (Fig. 8 ), and this agrees with Lee et al. [32] that revealed breast lesions in young females' biopsy should be considered in the event of abnormal imaging findings, such as non-circumscribed margins, complex solid and cystic components, posterior acoustic shadowing, size above $3 \mathrm{~cm}$, or an increase in mass size. A clinical history that includes a risk factor for malignancy, such as a family history of breast cancer, should prompt consideration of biopsy even if the lesion has a probably benign appearance. In our study, there is no significant difference between ultrasonography and MRI for diagnosis, and $p$ value is more than 0.05 and this agrees with Qiaohong and Jianwu [33]. Any female patients with a palpable breast mass who are under the age of 25 years, ultrasound should be the initial imaging modality [34]. Our study has a limitation that it was a retrospective study with a small sample size of malignant lesions; however, our patient group size is still considerable because breast cancer in women under 25 years of age is quite rare. This study shows the importance of ultrasonography in the diagnosis of palpable breast mass in women under 25 years which were overwhelmingly benign.

\section{Conclusion}

Most breast lesions in young women are benign. Ultrasonography is an essential first imaging modality in the diagnosis of women under 25 years with breast lesions.

\section{Abbreviations}

CT: Computed tomography; MRI: Magnetic resonance imaging;

ACR: American College of Radiology; BI-RADS: Breast Imaging-Reporting and Data System; US: Ultrasonography; MIP: Maximum intensity projection; 2D: 2 dimension; 3D: 3 dimension; NME: Non-mass enhancement

\section{Acknowledgements}

Not applicable

\section{Authors' contributions}

MMH carried out the radiological studies, participated in design of the study, AS and HQ collected the patients' data, MMH performed the statistical analysis. AA participated in the sequence alignment and drafted the manuscript. MH participated in the acquisition of data. WH participated in the sequence alignment. SA participated in the design of the study and performed the statistical analysis. HM conceived of the study, participated in its design and coordination, and helped to draft the manuscript. MMH wrote the paper with revision. All authors read and approved the final manuscript.

\section{Funding}

This study had no funding from any resource.

\section{Availability of data and materials}

The datasets used and/or analyzed during the current study are available from the corresponding author on reasonable request.

\section{Ethics approval and consent to participate}

This study was approved by the Research Ethics Committee of KAAH (King Abdul-Aziz Hospital) in Holy Makkah, Saudi Arabia. The patients were less than 16 years old at the time of the study, and written informed consent for their participation was given by their parent or legal guardian. The patients were more than 16 years old at the time of the study, and written informed consent for their participation was given. The committee's reference number is H-02-K-076-1912-238.

\section{Consent for publication}

All patients were less than 16 years old, and written informed consent for the publication of this data was given by their parent or legal guardian. All patients were more than 16 years old at the time of the study, written informed consent for their participation was given.

\section{Competing interests}

The authors declare that they have no competing interests.

\section{Author details}

1KAAH (King Abdul-Aziz Hospital), Holy Makkah, Kingdom of Saudi Arabia. ${ }^{2}$ Radiology Department, KAAH, Holy Makkah, Kingdom of Saudi Arabia. ${ }^{3}$ Radiology Department, Mansoura University, Mansoura, Egypt. ${ }^{4}$ Breast Unit Surgery Department, KAAH, Holy Makkah, Kingdom of Saudi Arabia.

${ }^{5}$ Pathology Department, KAAH, Holy Makkah, Kingdom of Saudi Arabia. ${ }^{6}$ King Abdul-Aziz University, Jeddah, Kingdom of Saudi Arabia.

Received: 14 February 2020 Accepted: 27 May 2020

Published online: 11 June 2020

\section{References}

1. Ellen MC, Regino C, Gregory JH et al (2009) Breast masses in children and adolescents: radiologic-pathologic correlation. RadioGraphics 29:907-931

2. Venta LA, Dudiak CM, Salomon CG et al (1994) Sonographic evaluation of the breast. RadioGraphics 14:29-50

3. Dehner LP, Hill DA, Deschryver K (1999) Pathology of the breast in children, adolescents, and young adults. Semin Diagn Pathol 16:235-247

4. Weinstein SP, Conant EF, Orel SG et al (2000) Spectrum of US findings in pediatric and adolescent patients with palpable breast masses. RadioGraphics 20:1613-1621

5. A. American College of Radiology. BI-RADS —Ultrasound. 1st ed. In: Breast Imaging Reporting and Data System (BI-RADS) atlas. 5th ed. Reston, Va: American College of Radiology, 2010.

6. Hong AS, Rosen EL, Soo MS et al (2005) BI-RADS for sonography: positive and negative predictive values of sonographic features. AJR Am J Roentgenol 184(4):1260-1265

7. Soo MS, Kornguth PJ, Hertzberg BS (1998) Fat necrosis in the breast: sonographic features. Radiology 206(1):261-269

8. Sughra R, Allison LG, Sona AC et al (2010) US of breast masses categorized as BI-RADS 3, 4, and 5: pictorial review of factors influencing clinical management. RadioGraphics 30:1199-1213

9. Stavros AT, Thickman D, Rapp CL et al (1995) Solid breast nodules: use of sonography to distinguish between benign and malignant lesions. Radiology 196:12334

10. Raza S, Chikarmane SA, Neilsen SS et al (2008) BI-RADS 3, 4, and 5 lesions: value of US in management-follow-up and outcome. Radiology 248(3): 773-781

11. American College of Radiology (2003) BI-RADS ${ }^{\oplus}$ —mammography. In: Breast Imaging Reporting and Data System (BI-RADS) atlas, 4th edn. American College of Radiology, Reston, Va

12. Mahoney MC, Gatsonis C, Hanna L et al (2012) Positive predictive value of BI-RADS MR imaging. Radiology 264:51-58

13. American College of Radiology. BI-RADS —MRI. 1st ed. In: Breast Imaging Reporting and Data System (BI-RADS) atlas. 5th ed. Reston, Va: American College of Radiology, 2010.

14. Malik R, Bharadwaj VK (2003) Breast lesions in young females-a 20-year study for significance of early recognition. Indian J Pathol Microbiol 46:559562

15. Leong SP, Shen ZZ, Liu TJ et al (2010) Is breast cancer the same disease in Asian and Western countries? World J Surg. 34:2308-2324 
16. Olu-Eddo AN\& Ugiagbe EE. (2011) Benign breast lesions in an African population: a 25-year histopathological review of 1864 cases. Niger Med J. 52(4):211-216

17. Egwuonwu OA, Anyanwu S, Chianakwana GU et al (2016) Fibroadenoma: accuracy of clinical diagnosis in females aged 25 years or less. Niger J Clin Pract 19:336-338

18. Valeur NS, Rahbar H, Chapman T (2015) Ultrasound of pediatric breast masses: what to do with lumps and bumps. Pediatr Radiol 45:1584-1599

19. Greydanus DE, Matytsina L, Gains M (2006) Breast disorders in children and adolescents. Prim Care 33:455-502

20. Millet I, Pages E, Hoa D et al (2012) Pearls and pitfalls in breast MRI. Br J Radiol. 85(1011):197-207

21. Coffin CM (2002) The breast. In: Stocker JT, Dehner LP (eds) Pediatric pathology, 2nd edn. Lippincott Williams \& Wilkins, Philadelphia, Pa, pp 993-1015

22. Chen Y, Bekhash A, Kovatich AJ et al (2015) Positive association of fibroadenomatoid change with HER2-negative invasive breast cancer: a cooccurrence study. PLOS ONE 10(6):e0129500

23. Yoon Y, Dhananjay C (2013) Adenomyoepithelioma of the breast: a brief diagnostic review. Arch Pathol Lab Med 137(5):725-729

24. Guray M, Sahin AA (2006) Benign breast diseases: classification, diagnosis, and management. Oncologist. 11(5):435-449

25. Chung EM, Cube R, Hall GJ, González C et al (2009) From the archives of the AFIP: breast masses in children and adolescents: radiologic-pathologic correlation. Radiographics 29:907-931

26. Gao Y, Saksena MA, Brachtel EF et al (2015) How to approach breast lesions in children and adolescents. Eur J Radiol 84:1350-1364

27. Ashikari H, Jun MY, Farrow JH et al (1977) Breast carcinoma in children and adolescents. Clin Bull. 7:55-62

28. Ambreen M, Tahir SM, Gulshan AS et al (2011) Breast lumps in adolescent and young female: are all benign. Journal of the Liaquat University of Medical and Health Sciences 10:3

29. Bullier G, MacGrogan H, Bonnefoi $G$ et al (2013) Imaging features of sporadic breast cancer in women under 40 years old: 97 cases. Eur. Radiol. 23:3237-3245

30. Gordon PB (1995) US problem solving in breast imaging: tricks of the trade. RSNA categorical course in breast imaging:121-131

31. An YY, Kim SH, Kang BJ et al (2014) Characteristic features and usefulness of MRI in breast cancer in patients under 40 years old: correlations with conventional imaging and prognostic factors. Breast Cancer 21:302-315

32. Lee EJ, Chang Y-W, Oh JH et al (2018) Breast lesions in children and adolescents: diagnosis and management. Korean J Radiol 19(5):978

33. Qiaohong P, Jianwu JI (2019) Diagnostic value of ultrasound combined with magnetic resonance imaging in different stages of breast cancer. Oncol Lett 17:209-214

34. Jackson VP (1995) The current role of ultrasonography in breast imaging. Radiol Clin North Am 83:1161-1170

\section{Publisher's Note}

Springer Nature remains neutral with regard to jurisdictional claims in published maps and institutional affiliations.

\section{Submit your manuscript to a SpringerOpen ${ }^{\circ}$ journal and benefit from:}

- Convenient online submission

- Rigorous peer review

- Open access: articles freely available online

- High visibility within the field

- Retaining the copyright to your article

Submit your next manuscript at $\boldsymbol{\nabla}$ springeropen.com 